\title{
A Estratégia Saúde da Família como Objeto de Educação em Saúde'
}

\section{The Family Health Strategy as object of Health Education'}

\section{Candice Boppré Besen}

Cirurgiã-dentista, Especialista em Saúde da Família pela Universidade Federal de Santa Catarina (UFSC).

E-mail: candice_boppreœbol.com.br

Mônica de Souza Netto

Cirurgiã-dentista, Especialista em Saúde da Família pela Universidade Federal de Santa Catarina (UFSC). Prof. Substituta do Departamento de Estomatologia da Universidade Federal de Santa Catarina (UFSC)

E-mail: netto.monica®ig.com.br

\section{Marco Aurélio Da Ros}

Médico, Doutor em Educação, Prof. Titular do Departamento de Saúde Pública da Universidade Federal de Santa Catarina (UFSC).

E-mail: rosळccs.ufsc.br

\section{Fernanda Werner da Silva}

Assistente Social, Especialista em Saúde da Família pela Universidade Federal de Santa Catarina (UFSC).

E-mail: nandawerner2000®yahoo.com.br

\section{Cleci Grandi da Silva}

Enfermeira, Especialista em Saúde da Família pela Universidade Federal de Santa Catarina (UFSC).

E-mail: aline_grandiøhotmail.com

\section{Moacir Francisco Pires}

Psicólogo, Especialista em Saúde da Família pela Universidade Federal de Santa Catarina (UFSC), Mestre em Educação pela UFSC. E-mail: moacirfranciscopæyahoo.com.br

I Artigo elaborado a partir do Trabalho de Conclusão do Curso de Especialização em Saúde da Família da Universidade Federal de Santa Catarina (UFSC).

\section{Resumo}

Este estudo investigou se a proposta da Estratégia Saúde da Família (ESF) é objeto de discussão com a população na prática educativa dos profissionais nela inseridos e a compreensão sobre Educação em Saúde que eles possuem. Trata-se de uma pesquisa qualitativa, exploratório-descritiva, realizada a partir de entrevistas semi-estruturadas. Na análise de conteúdo, identificaram-se as categorias: Educação em Saúde; A Universidade não ensina e A ESF como objeto de educação em Saúde. Os resultados mostraram que a ESF não é objeto de educação; alguns profissionais desconhecem seus fundamentos e a maioria deles tem práticas educativas verticais e patologizantes, distanciando-se da proposta de Promoção da Saúde da ESF. Reflete-se acerca das concepções de Educação em Saúde que permeiam os discursos dos profissionais, assim como sobre sua participação na capacitação comunitária para a construção da autonomia, cidadania e controle sobre os determinantes de saúde na perspectiva da Promoção da Saúde. Aponta-se para a importância da Educação Permanente e a reestruturação da graduação, de modo a aproximar as práxis da Educação em Saúde com a realidade social.

Palavras-chave: Saúde da Família; Educação em saúde; Recursos humanos em saúde. 


\section{Abstract}

This study investigated whether the proposal of the Family Health Strategy (FHS) is discussed with the population in the educational practice of the professionals inserted in this strategy, and the understanding of Health Education that these professionals have. It is a qualitative, exploratory-descriptive research, carried out through semi-structured interviews. The content analysis identified the following categories: Health Education;

The University does not teach; and FHS as Object of Health Education. The results showed that FHS is not an object of education; some professionals are unaware of its principles and the majority of them has vertical educational practices based on diseases, which makes them distance themselves from the proposal of Health Promotion of the FHS. The study provides reflections on the conceptions of Health Education that pervade the discourse of the professionals, as well as on their participation in the community qualification for the construction of autonomy, citizenship and health determinants control in the Health Promotion perspective. The article points to the importance of Permanent Education and to the reorganization of undergraduate studies, so that the Health Education practice is closer to the social reality. Keywords: Family Health; Health Education; Health Manpower.

\section{Introdução}

O Programa Saúde da Família (PSF) teve início em meados de 1993, sendo regulamentado de fato em 1994, como uma estratégia do Ministério da Saúde (MS) para mudar a forma tradicional de prestação de assistência, visando estimular a implantação de um novo modelo de Atenção Primária que resolvesse a maior parte (cerca de $85 \%$ ) dos problemas de saúde (Roncolleta, 2003; Da Ros, 2006).

O PSF visa ao trabalho na lógica da Promoção da Saúde, almejando a integralidade da assistência ao usuário como sujeito integrado à família, ao domicílio e à comunidade. Entre outros aspectos, para o alcance deste trabalho, é necessária a vinculação dos profissionais e dos serviços com a comunidade, e a perspectiva de promoção de ações intersetoriais (Da Ros, 2006; Brasil, 1997; Roncoletta, 2003).

Obter profissionais aptos a trabalharem nesse novo modelo e repensar as práticas educativas dentro da visão de Promoção da Saúde não se constitui uma tarefa fácil (Gil, 2005; Brasil, 2003; Brasil, 2005a). Conforme Cutolo (2000), essa dificuldade acontece como reflexo do modelo de formação destes profissionais: hospitalocêntrico, biologicista, fragmentado. Essas características, do chamado modelo flexneriano, utilizam metodologia de ensino verticalizada e não problematizadora, ou, como dito por Freire (2005), uma "educação bancária".

Esse modo de pensar e de fazer a Educação em Saúde faz parte do Estilo de Pensamento (EP) hegemônico, até hoje adotado nas Universidades. Cutolo (200o) entende Estilo de Pensamento como modos de ver, entender e conceber, que levam a um corpo de conhecimentos e práticas compartilhados por um coletivo com formação específica. Para Da Ros (200o), um coletivo de pensamento possui uma linguagem específica, que utiliza certos termos técnicos e um direcionamento das observações, dos problemas e métodos que passam a ter traços comuns.

Nas universidades, os EPs sobre o tema Educação em Saúde são caracterizados por Da Ros (200o) em dois estilos: a educação crítico-reflexiva e a educação com foco na culpabilização da população.

Sobre a educação crítico-reflexiva, mais compatível com o modelo de Promoção da Saúde e estruturada no modelo de Produção Social da Saúde, Da Ros (200o) 
coloca que a base histórica para esse EP se encontra na Teoria da Medicina Social, que surgiu na Europa em meados de 1800 , e segundo a qual o conceito de saúde tem suas bases na Determinação Social do processo saúde-doença. Nesse estilo, a educação é uma prática libertadora, de relação bilateral entre educador e educando, em que a postura verticalizadora é criticada. Para Buss (2003), esse modelo apresentase como uma estratégia de mediação entre as pessoas e seu ambiente, combinando escolhas individuais com responsabilidade social pela saúde, as chamadas políticas públicas saudáveis.

A educação culpabilizadora, a qual Da Ros (200o) denomina de Educação Sanitária, enfatiza um EP hegemônico na formação, em que educar em saúde é praticar higiene como forma de mudar comportamentos pessoais, para que não haja o adoecimento. A higiene individual deve ser de responsabilidade do indivíduo, para evitar a presença do agente causal, em uma visão claramente biologicista. Há uma negação explícita na determinação social do processo saúdedoença (Da Ros, 200o). Nesse caso, o lócus de responsabilidade e a unidade de análise são o indivíduo, que é visto como o último responsável (senão o único) por seu estado de saúde. Esse foco sobre o indivíduo e seu comportamento tem sua origem na tradição, na intervenção clínica e no paradigma biomédico (Buss, 2003).

Esse EP gera um modelo de trabalho na saúde que contempla atividades predominantemente curativas e reabilitadoras. Não há espaço para a integralidade da atenção, com a incorporação das ações de Promoção da Saúde, entendidas como o processo de capacitação da comunidade para atuar na melhoria da sua qualidade de vida e saúde, incluindo sua maior participação no controle desse processo (Brasil, 2003).

Segundo Lefèvre e Lefèvre (2004), quando há ações de Educação em Saúde no modelo culpabilizante de educação, geralmente o profissional acredita estar socialmente investido de autoridade sanitária. Ele pensa possuir, sob monopólio, o conhecimento verdadeiro e absoluto dos temas que envolvem saúde e doença; dessa forma, impõe, em nome de interesses maiores da coletividade, o tipo de comportamento que os indivíduos devem assumir.

O diálogo educativo entre as autoridades sanitárias investidas de funções educativas e informativas e as populações torna-se um mero discurso, se não vier acompanhado de um movimento de fortalecimento, empowerment (empoderamento), econômico, político, social e cultural dos indivíduos e grupos socialmente subordinados (Lefèvre, Lefèvre, 2004).

É cada vez mais necessário "oferecer oportunidades para que as pessoas conquistem a autonomia necessária para a tomada de decisão sobre aspectos que afetam suas vidas" e "capacitar as pessoas a conquistarem o controle sobre sua saúde e condições de vida" (Pereira e col. apud Lefèvre, Lefèvre, 2004, p. 152).

A autonomia, dessa forma, significa a possibilidade de o indivíduo escolher entre as alternativas e as informações que lhe são apresentadas de forma esclarecida e livre. Na perspectiva da Promoção da Saúde, os profissionais devem estabelecer vínculos e criar laços de co-responsabilidade com os usuários que irão decidir o que é bom para si, de acordo com suas próprias crenças, valores, expectativas e necessidades (Brasil, 1997; Pedrosa, 2003). A pessoa autônoma necessita de liberdade para manifestar sua própria vontade, além de capacidade de decidir de forma racional, optando entre as alternativas que lhe são apresentadas, bem como compreender as conseqüências de suas escolhas (Pedrosa, 2003).

Partindo-se da importância de os profissionais da saúde estarem aptos a trabalhar sob a lógica da Promoção da Saúde, este estudo investigou a compreensão sobre Educação em Saúde de cirurgiões-dentistas, enfermeiros e médicos inseridos na Estratégia Saúde da Família (ESF). Considerando-se a necessidade do fortalecimento da capacitação da comunidade no controle sobre os determinantes de sua saúde, procurouse identificar se esses profissionais trocam informações ou promovem discussão com a população sobre a proposta da ESF.

\section{Percurso Metodológico}

Este estudo baseia-se em uma pesquisa de campo qualitativa, do tipo exploratório-descritiva. Para sua execução, procurou-se compreender a essência dos fenômenos que envolvem o tema proposto, contemplando as relações sociais, entendendo os determinantes e os modos pelos quais se organizam na sociedade e a explicam.

Os dados foram coletados nos meses de setembro e outubro de 2005, a partir de entrevistas semi-estruturadas e diário de campo, cujo questionário foi sub- 
metido a um pré-teste com três profissionais. As entrevistas foram gravadas e guiadas por duas questões centrais: "O que você entende por educação em saúde?", "Você explica o que é PSF para os usuários?”. Foram entrevistados onze profissionais que atuam, no mínimo, há um ano em unidades de saúde de Florianópolis, inseridos nas equipes da ESF. Para definir o número de entrevistados, utilizou-se o recurso do esgotamento do discurso.

Inspirada por Minayo (1994) e Bardin (1977), a análise das entrevistas foi realizada conforme processo de ordenação dos dados, processo de categorização inicial, processo de reordenação dos dados empíricos e processo de análise final.

Como se trata de pesquisa envolvendo seres humanos, o projeto desta pesquisa foi submetido à aprovação do Comitê de Ética em Pesquisa da Universidade Federal de Santa Catarina (UFSC) - projeto 281/05 de acordo com a resolução do Conselho Nacional de Saúde (CNS), nº196/96. Cada entrevistado assinou um termo de consentimento, declarando sua livre participação na pesquisa, após ter recebido os devidos esclarecimentos sobre objetivos e método do estudo. Assim, para a preservação de sua identidade, utilizaram-se codinomes (E1, E2, E3 etc.).

Nesta pesquisa, originalmente, emergiram oito categorias de temas distintos. Para a temática de Promoção e Educação em Saúde, à qual se destina este artigo, destacam-se três destas categorias: Educação em Saúde (com as subcategorias educação patologizante e vertical, educação promotora de saúde e educação horizontal centrada na doença); Aprendi no Serviço/A Universidade não Ensina; e A Estratégia Saúde da Família como Objeto de Educação em Saúde, desdobradas conforme se segue.

\section{Educação em Saúde}

Esta categoria reúne elementos que identificam as concepções de Educação em Saúde que permeiam os discursos dos profissionais da Estratégia Saúde da Família. Assim, achamos necessário decompor essa categoria em três subcategorias.

\subsection{Educação Patologizante e Vertical}

Esta subcategoria baseou-se nos profissionais que possuem um Estilo de Pensamento (EP) curativista na Educação em Saúde, com foco nas patologias, e impositivo na relação profissional-paciente. A maio- ria dos entrevistados, no total de seis, apontam para essa lógica do processo educativo, em que os discursos são permeados por orientações preventivistas. Aqui a idéia é educar para prevenir.

Vaitsman (1992) afirma tratar-se de uma herança do modelo cartesiano que ainda domina as práticas educativas e de saúde. Se, por um lado, apresenta melhorias das condições de saúde da população, aumento da perspectiva de vida, por outro, desenvolve uma sociedade medicalizada, estruturada em uma tecnologia médica de alto custo, com enfoque reducionista, que sempre parece correr atrás de respostas para as doenças produzidas pelo modo de organização da vida social (Stotz, 1993; Illich, 1990; Gazzinelli e col., 2005).

Assim, o conhecimento científico e a tecnologia de alto custo têm posição de destaque passando a ser divulgados como verdade. Passaram a opor e, até mesmo, a desprezar o senso comum; ou seja, negam e tratam como "erro" o modo como as classes populares, teoricamente não detentoras deste conhecimento "oficial”, entendem e explicam o mundo (Valla, 20oo; Fonseca, 200o).

Para Pedrosa (2003), essa concepção científica, que poderíamos chamar de clássica, impregna as ações ditas pedagógicas nos serviços de saúde, com o agravante de serem pontuais e focalizadas nas especificidades de cada programa, intervenção ou situação. Dessa forma, são desenvolvidas ações educativas, por exemplo, para diabéticos, hipertensos, cardíacos, gestantes, nutrizes, adolescentes e outros, tipificando cada ser humano com o grau de risco que determinado modo de viver o enquadra.

O Estilo de Pensamento nas ações educativas desta subcategoria preconiza, verticalmente, a adoção de novos comportamentos, como por exemplo, "parar de fumar, vacinar-se, ter melhor higiene, entre outros, e de estratégias geralmente ditas coletivas, como a comunicação de massa" (Stotz, 1993).

Seguindo essa concepção, percebe-se que a fala está voltada para a prevenção de doenças:

Educação em Saúde são os procedimentos que você faz, que você agrega à comunidade que você trabalha para prevenir as doenças [...] Então, são todas as ações básicas simples que você possa formar a cabeça daquelas pessoas com as quais a gente trabalha. São noções básicas de higiene. $\left(\varepsilon_{1}\right)$ 
Esse modo de pensar a Educação em Saúde tem sempre um agente externo causador da doença que deve ser combatido como o "inimigo". É o caso do cigarro, que causa câncer e doenças coronarianas; do açúcar e do sal, que causam a diabetes e a hipertensão arterial; das gorduras, que causam o aumento do colesterol e o infarto, a obesidade e assim por diante (Laplantine, 1991).

Reforça-se nesse depoimento, o modelo biológico ou "exógeno" do adoecimento, segundo Laplantine (1991).

Oriento que não se deve comer fora de hora, falo bastante sobre doces, perguntando: Tu adoças muito o café ou suco? Não tem problema fazer isso, não é que não se possa comer bala ou adoçar muito o suco para quem gosta de doce, mas tem que saber que após, tem que escovar os dentes e não após muitas horas. Eu sempre falo isso. $\left(\varepsilon_{2}\right)$

Para Buss (2003), a prevenção difere-se da promoção, porque direciona mais às ações de detecção, o controle e o enfraquecimento dos fatores de risco ou fatores causais de grupo de enfermidades ou de uma enfermidade específica; seu foco é a doença e os mecanismos para atacá-la, mediante o impacto sobre os fatores mais íntimos que a geram ou a precipitam.

Nota-se que além de centrar-se na doença, a educação, nessa subcategoria, segue um modelo tradicional de imposição de conhecimentos ao paciente. Quando a relação linear entre o saber instituído e o comportamento acontece, via de regra, a educação se torna normativa (Gazzinelli e col., 2005). É muito comum encontrar atividades educativas que fazem uma transposição para o grupo da prática clínica individual e prescritiva, tratando a população usuária de forma passiva, transmitindo conhecimentos técnicos sobre as patologias e como cuidar da saúde, desconsiderando o saber popular e as condições de vida dessas populações. Muitas vezes, a culpabilização do próprio paciente por sua doença predomina na fala do profissional de saúde, mesmo que ele saiba dos determinantes sociais da doença e da saúde (Vasconcelos, 2000 apud Valla, 20oo; Briceño León, 1996).

O princípio que está por trás da norma de comportamento é a de que alguém, além do sujeito, conhece melhor o que é apropriado para ele e para todos, indistintamente:

Educação em Saúde são ações que partem do serviço, dos profissionais em direção ao usuário, no sentido de ajudar o usuário no seu entendimento sobre as questões de saúde, das questões dos cuidados que ele possa ter com o corpo etc. $\left(\varepsilon_{3}\right)$

Nas atividades ditas educativas, como as palestras e as aulas, sejam em grupos ou em consultas individuais, passa-se a idéia de que a doença se deve, principalmente, à falta de cuidado e ao desleixo da população com a sua saúde, deixando a "vítima" com sentimento de "culpa" pelo problema que apresenta. Como resultado dessa prática, dentre outros problemas, foram identificados por Chiesa e Veríssimo (2001), os seguintes: baixa vinculação da população aos serviços de saúde, baixa adesão aos programas e aos tratamentos e frustração dos profissionais de saúde.

Esses problemas ficaram evidentes nas entrevistas a seguir:

A gente não remarca, peço para que anote na caderneta e bote na geladeira. Os pais que têm interesse retornam, quando a gente marcava era um desastre total, a inadimplência era grande. ( $\left.\varepsilon_{1}\right)$

Já tentamos fazer grupos algumas vezes, mas as pessoas não vêm (...) ( $\left.\varepsilon_{4}\right)$

Autores como Briceño-León (1996) e Cáceres (1995) deixam explícito o fato de que os programas de Educação e Saúde não devem se limitar a iniciativas que visem a informar a população sobre um ou outro problema. 0 trabalho educativo a ser feito deve extrapolar o campo da informação, integrar a consideração de valores, de costumes, de modelos e de símbolos sociais, que levam a formas específicas de condutas e práticas.

Ensinar é algo profundo e dinâmico; portanto, torna-se imprescindível a "solidariedade social e política”, para evitar um ensino elitista e autoritário, como quem tem o domínio exclusivo do "saber articulado" (Freire, 1997). Segundo esse autor, educar não é a mera transferência de conhecimentos, mas sim a conscientização e o testemunho de vida, do contrário não terá eficácia. A autonomia, a dignidade e a identidade do educando, no caso, a comunidade e seus sujeitos, têm de ser respeitadas, caso contrário, o ensino se tornará "inautêntico, palavreado vazio e inoperante".

Neste sentido, qualquer iniciativa de educação só toma dimensão humana quando se realiza a "expulsão do opressor de dentro do oprimido", como libertação da culpa (imposta) pelo "seu fracasso no mundo" (Freire, 2005). 
Freire (1997) insiste também na "especificidade humana” da educação, como competência profissional e generosidade pessoal, sem autoritarismos e arrogância. Só assim nascerá um clima de respeito mútuo e de disciplina saudável entre "a autoridade docente e as liberdades dos alunos, [...] reinventando o ser humano na aprendizagem de sua autonomia”.

\subsection{Educação Promotora de Saúde}

Nesta subcategoria, são reunidas as percepções dos profissionais que têm outro Estilo de Pensamento (EP), que está voltado para a Promoção da Saúde no seu processo de trabalho educativo. Embora não se tratando de uma pesquisa quantitativa, chama a atenção o dado de que somente três profissionais foram identificados dentro deste EP.

Neste EP, a Educação em Saúde é abordada como estratégia fundamental, entendida de forma ampliada e não somente como um momento cronológico anterior à doença. Isso só ocorre quando a Promoção da Saúde é vista como um jeito de pensar e de fazer a saúde, no qual as pessoas são vistas em sua autonomia e em seu contexto político e cultural como sujeitos capazes de superar o instituído e serem os seus próprios instituintes de um modo de vida saudável (Buss, 2003).

Nesse sentido, os entrevistados comentam:

A Educação em Saúde é uma educação diferente de consultório. É uma educação que leva em consideração as pessoas da comunidade, a questão cultural dela [...] $\left(\varepsilon_{5}\right)$

Então, em Educação em Saúde, tu quer que as pessoas saibam as coisas que tu sabe, mas aí vai muito a forma que tu faz isso, né? Por exemplo, a gente parte do pressuposto que quer promover a saúde e fazer prevenção de algumas doenças. Então, a gente vai pegar e dar uma palestra para as pessoas, aí não dá, né? [sorriu]. Não dá, tu não está utilizando o conhecimento das pessoas, não está sendo estratégico, não tá respeitando o conhecimento dessas pessoas, não está discutindo com elas, não está levando em consideração o que elas sabem, o contexto de vida que elas vivem, a história de vida deles para aquilo que tu queres buscar: a melhor qualidade de vida, daqueles tanto saudáveis como com os doentes. Você deve utilizar a sabedoria delas para tu discutires, fazer com que estas pessoas sejam agentes da melhora da qualidade de vida deles. (E6)
Aqui, são estabelecidas condições favoráveis à superação do caráter meramente instrumental da Educação em Saúde cujos princípios se apóiam exclusivamente no saber científico. À medida que se observa a progressiva importância conferida às representações e aos saberes do senso comum na relação dos sujeitos com a doença, mais apurada se torna a crítica ao absolutismo e à autonomia do saber científico. O saber científico desconsidera a dimensão socioeconômico-cultural do sujeito, tornando o processo educativo não eficaz, uma vez que suas intenções divergem da realidade social e não proporcionam uma interação efetiva. Se a educação não se voltar à realidade concreta do indivíduo ela não se realiza, pois extrapola o universo do qual ele faz parte (Vasconcellos, 2004; Valla, 200o).

Pedrosa (2003) defende que as práticas educativas devem considerar a construção compartilhada de saberes que fundamentam as visões de mundo das pessoas e respeitar esses saberes forjados no mundo da vida, potencializando, dessa forma, o protagonismo das pessoas e dos coletivos sociais.

Nessa perspectiva, as ações educativas assumem um novo caráter, mais aderente aos princípios propostos pela ESF, destacando-se o direito à saúde, como eixo norteador, e a capacidade de escolha do usuário, uma condição indispensável.

Assim, é fundamental que o setor saúde embase a educação não apenas na transmissão de conhecimentos historicamente acumulados, mas que, principalmente, trabalhe na perspectiva da construção de conhecimentos e de qualidade de vida por todos aqueles que a integram.

A fala a seguir expõe esse pensamento promotor de saúde e de qualidade de vida:

A gente está abrindo também espaço aqui na unidade para a comunidade realizar atividades que não envolva doença, como yoga, ginástica, resgate cultural, por exemplo. Nós temos a dona Lurdes, que é nossa anciã, ela faz renda de bilro e pensamos dela fazer aula de renda de bilro. Tem também o motorista da ambulância que toda vida dele ele fez rede de pesca. $E$ isso está se perdendo, a importância cultural, está se perdendo. A dona Lurdes fala igual manezinha ${ }^{2}$ e não tem vergonha. Já os filhos mais velhos dela falam mais

2 Denominação popular para a pessoa nascida em Florianópolis. 
ou menos, e o mais novo faz questão de dizer que não é mané, então, isso está se perdendo. Outra idéia também seria a projeção de filme por semana, algo mais cultural. $\left(\varepsilon_{5}\right)$

A Promoção da Saúde, na prática das ações de educação, pressupõe que os indivíduos aumentem o controle sobre suas vidas através da participação em grupos, visando transformar a realidade social e política. Assim, há uma profunda distinção da abordagem tradicional centrada na mudança de comportamento individual. Assim, a prevenção dos agravos à saúde não é tratada isoladamente, mas como uma das metas a serem atingidas para a melhoria da qualidade de vida e para a justiça social (Valla, 200o; Stotz, 1993)

Nesta subcategoria, as condições de vida e a estrutura social são colocadas como as causas básicas dos problemas de saúde. Neste enfoque, a Educação em Saúde é entendida "como uma atividade cujo intuito é o de facilitar a luta política pela saúde" (Valla, 2000).

\subsection{Educação Horizontal Centrada na Doença}

Nesta subcategoria, parece surgir um terceiro EP em Educação em Saúde. As diferenças de EP, distanciamentos (ou proximidades), ou diferenças na precisão dos limites entre alguns Estilos de Pensamento são chamados por Fleck (1986) de matizes de Estilo de Pensamento (Fleck, 1986; Cutolo, 200o).

A relação profissional-paciente aparece de modo horizontal, sem imposição ou autoritarismos; entretanto, não consegue se despir do rigor do conhecimento científico voltado para a prevenção, para o biológico, como verdade absoluta e única a ser inserida no conhecimento dos indivíduos. Percebe-se que o profissional, teoricamente, tem a consciência da necessidade de considerar o conhecimento do paciente, respeita sua cultura e troca experiências com ele, porém seu discurso não se descola do "tema" doença. Esse estilo de pensar, para Mendes (1985), tem sua fundamentação advinda do aparelho formador ainda Flexneriano.

No processo educativo, o profissional parte do conhecimento do paciente, mas não promove saúde no seu conceito amplo, seu foco educativo está direcionado às doenças:

A educação não é feita toda de uma vez, é aos poucos, partindo do que ele já sabe, perguntando: o que o se- nhor ou a senhora sabe sobre sua doença? o que ouviu falar? O senhor/senhora conhece alguém com este problema? Como essa pessoa vive? $\left(\varepsilon_{7}\right)$

Os profissionais de saúde acreditam que o modo de vida dos indivíduos pode ser a causa de doenças e que, quando necessário, sem autoritarismos, ele deve ser mudado com base no que é considerado comportamento correto, conforme o ponto de vista biomédico. Este pressuposto, segundo Illich (1990), pode levar o comportamento humano à dependência de uma definição médica de "correção", ou ao que tem sido chamado de "medicalização da vida". Isso pode ser considerado um problema, porque pressupõe a aceitação social da medicina como fonte legítima de verdade, apesar da postura aberta de alguns profissionais aos valores e cultura dos indivíduos, constituindo-a em uma instituição de controle social.

A ideologia do individualismo tem conduzido à escolha do convencimento como principal estratégia educativa do modelo tradicional de educação em saúde (Mendes, 1985). Modos de vida não saudáveis, que fogem às regras, são relacionados à ignorância dos indivíduos quanto ao "correto" estilo de vida, segundo a visão biomédica. Ao instruir os indivíduos quanto à relação entre o comportamento "incorreto" e as patologias, os educadores em saúde esperam persuadi-los a assumir diferentes condutas.

Mesmo aquele profissional que busca acolher e ver os sujeitos enquanto integrantes de um meio sociocultural diverso acaba por "deslizar" no rigor do seu conhecimento científico profissional a medida em que impõe regras comportamentais, como se percebe a seguir:

Não é só aquela consulta de você chegar e dar remédio. As pessoas me procuram muito mais pra conversar, pra ter alguém que ouça. [...] Quando eu atendo primeiro o paciente eu digo que a pressão dele está alta, porque ele está comendo muito salgado ou não está caminhando e não está tomando muito líquido. Aí ele [o usuário] vai sair daqui com uma informação maior. Vai pensar melhor nisso aí, no que fazer. Porque não é uma vez que você consegue mudar o hábito de vida de uma pessoa. E ele [o usuário] vindo e tu falando sempre a mesma coisa para ele, a gente cobrando não consegue assim uns $100 \%$, mas aos pouquinhos, de grãozinho em grãozinho (...) (E8) 


\section{Aprendi no Serviço/ A Universidade não Ensina}

A capacitação dos profissionais nos cursos da área da saúde tem demonstrado limitações quanto à formação básica, no caso desta pesquisa, na ESF. Essas limitações podem ser percebidas, conforme alguns depoimentos dos profissionais quando questionados onde aprenderam a fazer Educação em Saúde:

Na universidade eu sei que não foi. Foi com os pacientes mesmo, né? Nós trabalhamos muito próximos das comunidades em Florianópolis, isto é muito real. [...] $\varepsilon$ aprende. $\bar{E}$ uma troca. Na realidade sai uma troca. $\varepsilon u$ já aprendi muito com meus pacientes. ( $\left.\varepsilon_{9}\right)$

A atual formação das Universidades gera um modelo de trabalho na saúde que contempla atividades predominantemente curativas e reabilitadoras, não permitindo a integralidade da atenção, em que as ações de saúde devem também incorporar as práticas educativas promotoras de saúde (Brasil, 2003). A maioria dos profissionais que atuam no Sistema Único de Saúde (SUS) ainda segue esse modelo, curativista, que não abre espaço para as práticas de educação e saúde efetivas (Pedrosa, 2003).

Além disso, percebe-se, nos depoimentos, que a Universidade tem sido uma instituição de ensino que usa do método de transmissão de conhecimento, basicamente de maneira verticalizada, negligenciando o processo de ensino-aprendizagem e a interação do educador-educando, conforme expressa a fala:

[Aprendi] No dia-a-dia, porque na Universidade até quando eu tava na graduação, é aquele grupo de sempre. A gente vai com a palestra pronta, e passa, igual na Universidade quando a gente assiste uma aula. Vai e fala o que é, e o que não é [...] e deu. E Educação em Saúde não é isso. (E1o)

É preciso que a universidade lance mão de uma "pedagogia não-normativa, problematizadora e dialogal" do tipo proposto por Freire (2002) na formação dos profissionais, para que eles possam, segundo Lefèvre e Lefèvre (2004), propiciar oportunidades de encontro e de troca entre o campo sanitário e o campo de senso comum e o fortalecimento deste último (associações de bairro, conselhos comunitários de saúde, clubes de mães etc.). Caso contrário, os profissionais acabarão sendo meros reprodutores daquela Educação em Saúde autoritária e prescritiva que os formou na universidade.
Da mesma forma, é essencial que o investimento na formação profissional não se limite à qualificação puramente técnica. A universidade precisa responder às necessidades da sociedade. 0 processo de formação que pretende ser eficiente jamais pode perder de vista a importância da comunidade na definição de suas necessidades, pois a prestação de atendimento somente tem sentido quando responde às demandas dos usuários (Severino, 2002).

Sisson (2002) afirma que a ESF possui limitações em sua operacionalização relacionada aos recursos humanos, gestores e recursos financeiros. Entre esses limites, aparece com destaque a formação inadequada dos profissionais. Segundo a mesma autora, o modelo assistencial hegemônico mantém-se inalterado ao privilegiar a atenção individual e hospitalar. Conseqüentemente, na rede básica, as atividades centrais continuam sendo a consulta médica, realizada como pronto-atendimento, em prejuízo ao cuidado integral de atenção e ao controle sobre os determinantes principais das condições de saúde.

A necessidade de mudança no processo de trabalho, na gestão e na formação de recursos humanos é amplamente reconhecida e acompanhada de críticas à inércia do aparelho formador, às universidades, em que existe grande resistência e dificuldades de mudanças, e nas quais continuam sendo formados profissionais que realimentam modelos assistenciais que algumas reformas buscam superar. As críticas concentram-se na educação médica, embora estejam relacionadas à formação dos demais profissionais (Sisson, 2002).

\section{A Estratégia Saúde da Família como objeto de Educação em Saúde}

Essa categoria se propõe a trazer reflexões sobre a ESF como um possível objeto de Educação em Saúde para o acesso da população às informações sobre sua saúde, construção da cidadania e busca de autonomia. Pretende-se fomentar a socialização dos saberes acerca do ESF/SUS, com o intuito de incentivar a participação social nos determinantes de sua saúde.

A ESF, vista como objeto de Educação em Saúde, tem como papel central uma prática educativa voltada para a Promoção da Saúde, como um conjunto de atividades orientadas a propiciar o melhoramento de condições de bem-estar e acesso a bens e a serviços sociais. 
Dessa forma, os autores entendem que dedicar um espaço da Educação em Saúde para trabalhar questões que vão além do biológico com a população propulsionará o desenvolvimento de conhecimentos, atitudes e comportamentos favoráveis ao cuidado da saúde mediante o processo de empowerment e luta pelo alcance de estratégias que permitam um maior controle sobre suas condições de vida, individual e coletivamente.

A Educação em Saúde pode ser feita dentro da família, na escola, no trabalho ou em qualquer espaço comunitário. Este é um componente que está presente na Carta de Ottawa, resultante da I Conferência Internacional sobre Promoção da Saúde, em 1986, no Canadá, que resgata a dimensão da Educação em Saúde, além de avançar com a idéia de empowerment, ou seja, o processo de capacitação (aquisição de conhecimentos) e consciência política comunitária (Buss, 2003). A percepção de que a mudança na Educação em Saúde deve acompanhar a formação dos profissionais de saúde também está presente na declaração resultante desta conferência (Buss, 2003).

Segundo Pedrosa (2003), faz-se necessário repensar a Educação em Saúde sob a perspectiva da participação social; compreender que as verdadeiras práticas educativas só têm lugar entre sujeitos sociais e considerar a Educação em Saúde uma estratégia para a constituição de sujeitos ativos, que se movimentam em direção a um projeto de vida libertador.

Diante dessas e de outras considerações que são apresentadas neste estudo, a partir da análise de trechos das entrevistas realizadas, discute-se se os profissionais entendem a proposta da ESF e se trocam informações com a população sobre a ela.

Os trechos abaixo nos conduzem à reflexão sobre a relação imediatista e curativista à qual estão acostumados os profissionais da ESF, quando questionados se promovem discussão sobre a ESF com a população: Não. O pessoal quer saber, ao bater na porta ali, ó, que ele tá preocupado em resolver a necessidade dele, não quer saber se é $P S F .\left(\varepsilon_{1}\right)$

As colocações abaixo evidenciam, com transparência, a falta de esclarecimento à população sobre a que se propõe à ESF

Sabe que eu nunca parei para falar sobre isso. Na verdade, eles [os usuários] não têm uma noção boa ainda sobre o PSF. Acho que nem mesmo a gente tem. A gente fala que trabalha no PSF, mas eu nunca parei para explicar especificamente o PSF para o paciente. Até porque, deveria ter tempo, mas ele [o usuário] vem aqui com outras coisas, e a gente acaba conversando e não fala do programa. $\varepsilon$ uma lacuna mesmo. (E1o)

A partir da análise das considerações feitas pelos sujeitos de pesquisa, verificamos que, dos onze profissionais entrevistados, somente dois responderam que discutem com usuários a proposta da ESF:

[...] No grupo, quando se fala do Programa Saúde da Família, eles ficam bem interessados, eles perguntam, mas você tem de estimular. É difícil alguém chegar do nada e perguntar o que é PSF, a não ser quando uma semana depois que a gente publicou um jornalzinho local falando sobre o PSF. É outra forma que complementa. Tivemos uma tiragem de 8 mil exemplares, é pouco, mas são oito mil que lêem. ( $\left.\varepsilon_{5}\right)$

Para todos os entrevistados, se não fosse pela indução da pergunta, a ESF não iria surgir como proposta que faça parte da educação em saúde dos profissionais. Ela é considerada pelos autores como uma categoria por ausência.

Sugere-se, neste estudo, que os profissionais da ESF sejam capacitados a trabalharem neste novo modelo de saúde, pois, mediante as análises de conteúdo, constatou-se que muitos deles ainda não têm bem claro o que realmente seja a ESF e que, portanto, pouco têm a contribuir como multiplicadores de informações a esse respeito. Ocorre que o EP hegemônico ainda se pauta em um processo de ensino, para a formação universitária, que valoriza a prática intervencionista, com uma relação sujeito-objeto, e no modelo biologicista, que não trata de emponderar a população (Da Ros, 2004).

Por outro lado, podemos identificar que aqueles profissionais que tentam promover uma discussão com a população acerca dessa proposta não conseguem fazê-lo de modo mais aprofundado e contínuo, em função, entre outros, da demanda de usuários incompatível com a capacidade de atendimento. Além disso, os gestores (também malpreparados) não possibilitam a esses profissionais a possibilidade de Educação Permanente. Premidos pela formação flexineriana e pela realidade de um serviço que não valoriza a formação de saúde, o modelo não avança. (Brasil, 2003). Esse fato tende a fazer com que os processos de educação e comunicação na perspectiva da Promoção da Saúde sejam relegados a uma questão de segunda ordem. 


\section{Considerações Finais}

Constatou-se que a formação dos profissionais de saúde é uma das problemáticas centrais. Eles demonstram não estar preparados para o trabalho na lógica da Promoção da Saúde requerida pela ESF. Ao contrário, a maioria dos discursos é permeada por uma educação voltada para as doenças e para a tentativa de mudança de comportamento dos indivíduos, com relação vertical e impositiva. Por essa razão, reitera-se a relevância da Educação Permanente e da reestruturação da graduação, de modo a aproximar as práxis da Educação em Saúde da realidade social.

Assim, afirma-se que a Educação Permanente é aprendizagem no trabalho, em que o aprender e o ensinar se incorporam ao cotidiano das organizações deste trabalho. Propõe-se que os processos de capacitação dos trabalhadores da saúde tomem como referência as necessidades de saúde das pessoas e das populações e tenham como objetivos a transformação das práticas profissionais e da própria organização do trabalho, estruturadas a partir do processo de problematização (Brasil, 2003; Brasil, 2005a).

Além disso, propõe-se que o processo de trabalho dos profissionais da ESF possa ser um veículo de empoderamento da população mediante a discussão sobre o que propõe a ESF e/ou o SUS e como devem ser estruturados conforme a legislação.

Não somente os profissionais já formados e integrantes das equipes da ESF devem ser capacitados para uma Educação em Saúde adequada. Tendo em vista a importância de todo o processo de formação do profissional, eles precisam, desde a graduação, se formar na lógica do modelo da Determinação Social da Saúde, capacitando-se para trabalhar na ESF/SUS.

Assim, é essencial a articulação do Ministério da Saúde (MS)/Ministério da Educação e Cultura (MEC) a fim de efetivar a reforma curricular. O MS, por intermédio da Secretaria de Gestão do Trabalho e da Educação na Saúde (SGTES), em conjunto com a Secretaria de Educação Superior do Ministério da Educação (SESU/MEC), vem conduzindo o processo de implantação do Programa Nacional de Reorientação da Formação Profissional em Saúde - PRÓ-SAÚDE. Inspirado no que foi o PROMED, dirigido às escolas médicas, que incentivou e manteve 19 escolas médi- cas, incrementando processos de transformação, o PRÓ-SAÚDE tem como eixos básicos: a realização do ensino nos ambientes reais onde se dá a assistência à saúde pelo SUS, o uso de metodologias e estratégias educacionais, nas quais os estudantes assumam papéis mais ativos, e a própria expansão do objeto do ensino, que não deve ser apenas a doença já instalada, mas a Produção Social da Saúde como síntese de qualidade de vida. Essa iniciativa visa à aproximação entre a formação de graduação no país e as necessidades da Atenção Primária, que se traduzem no Brasil pela ESF. A desarticulação entre os mundos acadêmicos (saber científico) e o saber popular vem sendo apontada, em todo mundo, como um dos responsáveis pela crise do setor da saúde, no momento em que a comunidade global inicia a tomada de consciência acerca da importância da formação dos trabalhadores de saúde, valorizando-os cada vez mais (Brasil, 2005b; Brasil, 2003; Brasil, 2000).

\section{Referências}

BARDIN, L. Análise de conteúdo. São Paulo: Martins Fontes, 1977.

BRASIL. Ministério da Saúde. Portaria GM/MS nº 1882, de 18 de dezembro de 1997. Brasília, DF, 1997. Disponível em: <http:// www.saude.gov.br>. Acesso em: 20 ago. 2006.

BRASIL. Ministério da Educação. Minuta do Anteprojeto das Diretrizes Curriculares Nacionais para os cursos de graduação em medicina. Brasília, DF, 20oo. Disponível em: <http:// www.mec.org.br>. Acesso em: 30 dez. 2005.

BRASIL. Ministério da Saúde. Secretaria de Gestão do Trabalho e da Educação na Saúde. Departamento de Gestão da Educação na Saúde. Política de educação e desenvolvimento para o SUS. Brasília, DF, 2003. Disponível em: <http:// www.saude.gov.br>. Acesso em: 27 set. 2004.

BRASIL. Ministério da Saúde. Secretaria de Gestão do Trabalho e da Educação na Saúde. Departamento de Gestão da Educação na Saúde. A educação permanente entra na roda: pólos de educação permanente em saúde: conceitos e caminhos a percorrer. Brasília, DF, 2005a. 
BRASIL. Ministério da Saúde. Pró-saúde: Programa Nacional de Reorientação. Brasília, DF, 2005b. Disponível em: <http:// portal.saude.gov.br /saude>. Acesso em: 10 nov. 2005.

BRICEÑO-LEÓN, R. Siete tesis sobre la educación sanitaria para la participación comunitaria. Cadernos de Saúde Pública, Rio de Janeiro, v. 12, n. 7, p. 30, 1996.

BUSS, P. M. Uma introdução ao conceito de promoção da saúde. In: CZERESNIA, D. (Org.).

Promoção da saúde: conceitos, reflexões, tendências. Rio de Janeiro: Fiocruz, 2003. p. 15-38.

CÁCERES, C. F. La construcción epidemiológica del SIDA. In: HARDY, E.; OSIS, M.I.D.; CRESPO, E. R. (Org.). Ciências sociais e medicina, atualidades $e$ perspectivas latino-americanas. Campinas: Centro de Pesquisas Materno-Infantis de Campinas; 1995. p. 131-71.

CHIESA, A. M.; VERISSÍMO, M. R. A educação em saúde na prática do PSF: manual de enfermagem. Brasília, DF: Instituto para o Desenvolvimento da Saúde, 2001.

CUTOLO, L. R. A. Estilo de pensamento em educação médica: um estudo do currículo do Curso de Graduação em Medicina da UFSC. 20oo. Tese - UFSC, Florianópolis, 2000.

DA ROS, M. A. Estilos de pensamento em saúde pública: um estudo de produção FSP - USP e ENSP Fiocruz entre 1948 e 1994, a partir da epistemologia de Ludwick Fleck. 20oo. Tese (Doutorado em Educação e Ciência) - CED, UFSC, Florianópolis, 2000.

DA ROS, M.A. A ideologia nos cursos de medicina. In: MARINS, J. J. N. et al. (Org.). Educação médica em transformação: instrumentos para a construção de novas realidades. São Paulo: HUCITEC, 2004. p. 224244 .

DA ROS, M.A. Políticas públicas de saúde no Brasil. In: BAGRICHEVSKI, M. (Org.). Saúde em debate na Educação Física. Blumenau: Nova Letra, 2006. p.4466.

FLECK, L. La génesis y el desarollo de un hecho científico. Madrid: Alianza Editorial, 1986.
FONSECA, L. C. de S. Ensino de ciências e saber popular. In: VALLA, V. V. Saúde e educação. Rio de Janeiro: DP\&A, 20oo. p.87-104.

FREIRE, P. Pedagogia da autonomia: saberes necessários à pratica educativa. 5. ed. São Paulo: Paz e Terra, 1997.

FREIRE, P. Extensão ou comunicação. 12. ed. Rio de Janeiro: Paz e Terra, 2002.

FREIRE, P. Educação e mudança. 28. ed. São Paulo: Paz e Terra, 2005a.

FREIRE, P. Pedagogia do oprimido. 44. ed. São Paulo: Paz e Terra, 2005b.

GAZZINELLI, M. F. et al. Educação em saúde: conhecimentos, representações sociais e experiências da doença. Cadernos de Saúde Pública, Rio de Janeiro, v. 21. n. 1, jan./fev. 2005.

GIL, C. R. R. Formação de recursos humanos em saúde da família: paradoxos e perspectivas.

Cadernos de Saúde Pública, Rio de Janeiro, v. 21. n. 2, mar./abr. 2005 .

ILLICH, I. Limits to medicine - medical nemesis: the expropriation of health. London: Penguin Books, 1990.

LAPLANTINE, F. Antropologia da doença. São Paulo: Martins Fontes, 1991.

LEFEVRE, F.; LEFEVRE, A. M. C. Promoção de saúde, a negação da negação. Rio de Janeiro: Vieira \& Lent, 2004 .

MENDES, E. V. A evolução histórica da prática médica, suas implicações no ensino, na pesquisa e nas tecnologias médicas. Belo Horizonte: PUC-MG: FINEP, 1985.

MINAYO, M. C. S. O desafio do conhecimento: pesquisa qualitativa em saúde. 3. ed. São Paulo: HUCITEC; Rio de Janeiro: ABRASCO, 1994.

PEDROSA, I. I. É preciso repensar a educação em saúde sob a perspectiva da participação social. Disponível em: <www. gices-sc.org>. Acesso em: 20 out. 2005. Entrevista cedida a Radis, 2003.

RONCOLletA, A. F. T. et al. Princípios da medicina de família. São Paulo: Sombramfa, 2003. 
SEVERINO, A. J. Educação e universidade: conhecimento e construção da cidadania. Interface:

Comunicação, Saúde, Educação, Botucatu, v. 6, n. 10, p. 117-124, fev. 2002.

SISSON, M. C. Avaliação da implantação do programa de saúde da família no programa DocenteAssistencial de Florianópolis. 2002. Tese - Faculdade de Medicina da Universidade de São Paulo, São Paulo, 2002.

STOTZ, E. N. Enfoques sobre educação e saúde. In: VALLA, V. V; STOTZ, E. N. (Org.). Participação popular, educação e saúde: teoria e prática. Rio de Janeiro: Relume-Dumará, 1993. p. 11-22.
VAITSMAN, J. Saúde, cultura e necessidades. In: FLEURY, S. (Org.). Saúde coletiva?: questionando a onipotência do social. Rio de Janeiro: RelumeDumará, 1992. p. 157-173.

VALLA, V. V. Saúde e educação. Rio de Janeiro: DP\&A, 2000 .

VASCONCELOS, E. M. Formar bons lutadores para a saúde. Nós da Rede - Boletim da Rede de Educação Populare Saúde, Recife, n. 7, p. 2-3, dez. 2004. 